\title{
Research on eSourcing in Supply Chain Management
}

\author{
Jindi $\mathrm{Ji}^{1, \text { a }}$, Liang $\mathrm{Li}^{2, \mathrm{~b}}$ \\ ${ }^{1}$ Guangzhou Business College, Guangzhou 528138, China; \\ ${ }^{2}$ Tianjin Zhongshi Company, Tianjin 300000, China. \\ ajddear@foxmail.com, ${ }^{b}$ leonlee0704@163.com
}

Keywords: eSourcing, procurement, strengths and weaknesses

\begin{abstract}
This paper aimed at discussing eSourcing, which is a booming procurement strategy in various industries. Through the literature study, it presents different definitions of eSourcing and describes its characteristics, mainly analyzing the strengths and weaknesses of eSourcing. Finally, it makes a conclusion and illustrates the development of eSourcing in the future. With elaborate analysis, it can be summarized that eSourcing is a promising procurement method, which will be extensively used in both commerce and public departments.
\end{abstract}

\section{Introduction}

eSourcing uses computer technology to perform sourcing tasks and replace the traditional paper work. Specifically, purchasing information or bidding requirement can be published online and appropriate suppliers can be also selected on the eSourcing platform through real-time reverse auction between all suppliers. eSourcing is also called eProcurement and e-reverse auction. It is a modern procurement mode which is based on the traditional procurement mode.

There is a lot of research related to eSourcing, while there is still no consensus in terms of the definition of eSourcing. Some main standpoints are as follows.

Chaffey (2004) thinks eSourcing is a process that manage all purchasing businesses between suppliers and buyers, including proposing purchasing requirement, making purchasing plan, selecting suppliers, placing an order, delivery and payment. Toland (2006) presents that eSourcing is a way that companies buy products or service, publish purchasing demands, select suppliers, manage service, sign contracts and pay through internet system.

The Office of Government Commerce (OGC) suggests that electronic reverse auction is a way of online auction which allows eligible suppliers to submit their bidding prices on eSourcing platform. Such a procurement mode can be used to both commodity purchasing, engineering and service project. Thereby, it can be seen that eSourcing needs to be completed through internet system.

American Aberdeen Group demonstrates that eSourcing utilizes internet solution and decision tools to identify, evaluate and supervise procurement activities so as to support supply chain operation.

Group Supplies is a company offering professional procurement service and one of the services is Reverse E-auction which is called eSourcing in this research. Group Supplies define that eSourcing is a process that suppliers decrease the price online in real time.

Based on a series of definitions of electronic sourcing above, we define eSourcing as a real-time 
procurement way through online bidding system. Specifically, purchasing demand is made and price is the main criterion to decide the winning bidders, also including other supplements which can be quantified. The specified suppliers are invited to bidding online and the winning bidder will be awarded online according to the bidding rules.

The rest of this paper is organized as follows. In the next section, the characteristics of eSourcing will be presented including the strengths and weaknesses; Section three will illustrate exhaustive functions of eSourcing. The last section will make a conclusion and discuss the future development of eSourcing.

\section{Characteristics of eSourcing}

In this part, we summarize some characteristics of eSourcing. Firstly, eSourcing is a kind of purchasing activity using internet. Secondly, eSourcing is a process that suppliers keep cutting down their quote. Therefore, the core of eSourcing is the mechanism of continuous price reduction. Furthermore, eSourcing is a real time bidding. That is to say, suppliers log in the bidding platform and start the online bidding on time. Once time is up, the bidding will stop automatically. This is the main difference compared with traditional procurement. Another characteristic is that the criteria of selecting winning bidders is not only based on the quote, but some other key elements can be also considered as the rules of bid assessment. Thus, eSourcing can apply to engineering project and service area as well. Ultimately, the internet program can finish the evaluation of bidding and the bidding report can be performed automatically, which is the special characteristic of eSourcing. In this way, it ensures the whole bidding process is public and fair.

\subsection{Strengths of eSourcing}

In the past few years, procurement activity has begun to play an important role for companies in making decisions (Weele, 2010). eSourcing uses information technology to select suppliers online, bid online and awards winning bidders online with a range of benefits.

In eSourcing, the buyer invites pre-selected suppliers who compete against each other to supply specified goods or service, forcing a competitive price through direct bidding (De Boer et al., 2002). Not only does eSourcing improve the efficiency but also reduce the purchasing cost to a great degree. In specific, purchasers are able to select the most appropriate vendors through the bidding platform, which contributes to sufficient and complete competition. As a result, buyers succeed to obtain reasonable prices and reduce the purchase cost.

Another benefit is that eSourcing provides a wider choice of suppliers and increases the number of eligible suppliers. Thus, it solves the problem of the limited number of suppliers in traditional procurement activity. Electronic means globalize the purchasing activity and it is not restricted to a specified area and industry.

Moreover, eSourcing gives more transparency during the transaction. The eSourcing platform enables companies to monitor bidding process in real time and select winning bidder automatically. In this way, it avoids "black case work" and makes purchasing activity fairer.

One more advantage is that eSourcing facilitates information sharing among buyer and supplier enterprises. eSourcing encourages public competition among suppliers to provide more opportunities in market. Thereby, it optimizes the information flow in supply chain.

Additionally, eSourcing also optimizes the procurement process so that it decreases the procurement cycles. The process of eSourcing is much simpler and more rapid compared with traditional negotiation and quote. eSourcing makes all suppliers centralize in the eSourcing platform and thus all activities from bidding to awarding can be performed one by one. Consequently, it saves a lot of time and reduces the procurement cycles. 
As mentioned above, it can be seen that eSourcing is a necessary means for enterprises to strengthen its competitiveness in information age. From a perspective of global development of procurement trend, eSourcing is not only a critical form of e-commerce but it is an imperative tendency of procurement development. eSourcing changes the way of traditional purchasing.

\subsection{Weaknesses of eSourcing.}

Whereas, in spite of a great amount of advantages of eSourcing, there are also some weaknesses for enterprise to use eSourcing. Firstly, it takes a great amount of investment in research and development of the eSourcing system. As a result, it is an obvious obstacle for companies to adopt eSourcing. Although it takes a lot of finance capital in the beginning, it is still worth paying in long-term interest of the reduction of purchasing cost.

The second shortcoming is that eSourcing requires experienced IT staff to construct, utilize and maintain the eSourcing system. Also, it is necessary to train bidders to operate the eSourcing platform. While, as far as enterprises are concerned, sufficient professional IT staff is still a big challenge.

Another problem is malicious competition between suppliers. The computer program leads to intense price competition even price extremes which might be much lower than the initial margins of suppliers. Some suppliers might damage their own benefits in order to win the bid. For instance, they submitted a price which is much lower than its cost but regret to bid. In this case, suppliers are very likely to negotiate with buyers to recover their losses in the bidding, thereby questioning if eSourcing bidding process works for purchasing activity (Lapiedra et al., 2004). One more price drawback in tendering process is that the cheapest is not always the best deal, because other factors such as quality, delivery period, payment cycle and after-sales service also need to be concerned (Ray et al., 2007).

Also, the application and implementation of eSourcing is still a challenge for companies to overcome (Caniato, Longoni \& Moretto, 2012). There are several failure examples of eSourcing in practice. The main reason is that eSourcing strategy is much more complicated, time consuming and harder than original anticipation.

\section{3. eSourcing functions}

eSourcing can be regarded as the combination of diverse and complementary functions, among which a company can select proper one to its demand (Caniato, Longoni \& Moretto, 2012). It consists of all kinds of different tools. De Boer (2002) identified several forms of eSourcing: e-tendering, and e-informing, e-MRO and web-based ERP. The specific functions of eSourcing are listed as follows.

- Catalogue. Allowing buyers to make procurement demand, issue bidding information and check history purchasing events.

- RFX. Asking for a request for quotation, information or a request for proposal to the supplier.

- Online bidding. Inviting pre-selected suppliers to submit competitive prices through the eSourcing system during the opening time of bidding.

- Bidding monitoring. Allowing buyers to monitor the whole bidding process and handle any emergent issues during bidding if needed.

- Reporting. Allowing users to report bidding data including price record and bidding result.

- Evaluation. Allowing buyers to evaluate suppliers from different perspectives such as quotation, quality and service level, thus selecting the most qualified supplier.

- Awarded online. Allowing purchasers to award the most qualified supplier through the eSourcing system. 
- Order placement and tracking. Automating order emission from purchaser side to suppliers and allowing buyers to check order status and history record.

- E-Invoicing. Sending and receiving electronic invoices through the eSourcing platform and matching them with orders and delivery information automatically.

- Supplier management. Allowing buyers to assort suppliers and update supplier lists.

- Contract management. Sending and receiving electronic contract through the eSourcing platform and matching them with purchasing order automatically.

\section{Conclusions and future development}

In conclusion, when electronic ecommerce has mushroomed in B2B market, eSourcing is been extensively used between business partners over the world. It has made plentiful technological benefits over the last few years and is expected to make continuous improvement and promotion in its efficiency as well as productivity in near future. There are several popular eSourcing systems like Ariba, Oracle and Commerce One, which are applied to procurement activity already in a number of companies. In addition to eSourcing platform, some purchasing website also offer e-tendering service, for instance, SupplierMarket.com , BidtheWord.com, save33.com, eBreviate.com, ebay.com and alibaba.com. Whereas, it is also very common that large enterprises such as IBM, Microsoft and Dell research and develop their own eSourcing platform.

When it comes to eSourcing, the focus is mostly on commercial transactions between enterprises. While, it is also frequently used in public department like government procurement. The adoption of eSourcing in public sector institution tends to become increasingly popular these years. A bureaucratic purchasing procedure is substituted by eSourcing, which means enormous quantity of efforts spent on tedious process can be simplified. Given all information as mentioned above, we believe an increasing number of groups including businessman and public sectors will realize the importance of eSourcing. In spite of some shortcomings, we are confident that the progress of high technology in eSourcing platform will help solve the majority of problems. More attention will be paid to eSourcing and more benefits will be obtained in future purchasing activity.

\section{References}

[1] D. Chaffey. E-Business and E-Commerce Management (2nd Ed). London: Prentice Hall, 2004

[2] J. Toland. E-commerce in developing countries. Proceedings of Encyclopedia of ECommerce, Government and Mobile Commerce, 2006, 1: 308-313

[3] Aberdeen Group. Making e-sourcing strategic: from tactical technology to core business strategy. Technical Report, Aberdeen Group Inc., 2002

[4] DE BOER L., HARINK J. and HEIJBOER G. (2002) A conceptual model for assessing the impact of electronic procurement. European Journal of Purchasing and Supply Management 8(1), 25-33.

[5] Weele, Arijan van. Purchasing Supply Chain management. 5th revised edition, Cengage Learning, London, 2010.

[6] LAPIEDRA R., SMITHSON S., ALEGRE J. and CHIVA R. (2004) Role of information systems in the business network formation process: An empirical analysis of the automotive sector. The Journal of Enterprise Information Management 17 (3), 219-228.

[7] Ray Hackney, Andrea Loesch, Zahir Irani, Ahmad Ghoneim, Sevgi Ozkan, (2007) "Evaluating eReverse auctions (EeRA): A case research note", Transforming Government: People, Process and Policy, Vol. 1 Issue: 1, pp.59-66,

[8] Federico Caniato, Annachiara Longoni \& Antonella Moretto (2012) Effective eProcurement implementation process, Production Planning \& Control: The Management of Operations, 23:12, 935-949.

[9] DeBoer, L. Harink, J. et al. (2002). A Conceptual Model for Assessing the Impact of Electronic Procurement. European Journal of Purchasing and Supply management 8(1), 25-33. 